\title{
2020 and all that
}

This year is one that we will never forget. It actually didn't start that well for me, when I returned from a 3-week stint working for the World Health Organization (WHO) in Brazzaville in mid-December last year suffering with the virus from hell - presciently, as it turned out! Within a few weeks we would all, in differing ways, be facing the 'virus from hell. Early in 2020, a cluster of unusual pneumonias in Wuhan City, Hubai Province, China, first reported in December 2019, had hit the news. It very soon became clear that the causal virus, SARS-CoV-2, was going to spread around the world with unprecedented speed, causing the illness COVID-19. By 17 March 2020, all countries in Europe had reported at least one case of this new disease. As of 13 March, the WHO started to regard Europe as the active centre of what had by now been designated a pandemic. ${ }^{[1]}$ As the virus spread around the world, we watched in fascinated horror as Western countries were overwhelmed by the disease, with their hospital services buckling under the strain of admissions, unusually high numbers of people requiring treatment in intensive care units, and, as it quickly became clear, very high death rates among older people with multiple comorbidities. Successive waves of lockdowns were instituted across almost every country in the world. Stock markets fell. The travel industry was decimated as countries closed their borders. Life as we knew it came to a halt.

Africa was the last continent to be affected by the pandemic, with our first cases recorded in Egypt and Algeria in late February 2020 in travellers from Europe. The disease spread across the continent fairly rapidly, initially all through imported cases, and by 13 May, Lesotho became the final country to record cases ${ }^{[2]}$ Africa was expected to have a severe and devastating pandemic. With our fragile health systems and frequent outbreaks of infectious diseases, as well as large numbers of people living with HIV and tuberculosis, it was expected that we would be overwhelmed by infections and deaths. However, the current figures in Africa represent just 3\% of confirmed COVID19 cases and $2.5 \%$ of deaths reported worldwide. ${ }^{[3]} \mathrm{I}$ am not going to get into the validity of the figures for the African region, except to say that the excellent work being done by WHO epidemiologists in the region suggests that they are not as far off the mark as some people might think (work in progress and papers under review, but not yet published). However, that aside, we have had a hard few months in South Africa. I know from casual conversations I have had with our foremost clinicians and researchers that, at the peak in June, July and August, our hospitals and their staff were under enormous strain. And every death from the disease has been a tragedy for the family and friends of the person. The lockdowns that we have all endured since mid-March have taken their toll, sadly with little apparent effect on the trajectory of the pandemic in the country. We started the pandemic in a precarious economic situation and are now literally at a cliff edge from which we are going to struggle to recover, if indeed we ever do. For every person directly affected by COVID-19, there are uncountable numbers more whose lives will never be the same again as a result of our poorly judged and badly implemented lockdown. In addition, the pandemic has provided yet another opportunity for rampant theft and corruption among those connected to government, in everything from procurement of personal protective equipment to building field hospitals. We have also watched the more precariously placed health services of provinces such as Eastern Cape almost literally collapse under the strain of the disease.

But, uncharacteristically, I am going to finish on a note of hope and optimism. Not because I think 2021 will be much different. I don't. This virus isn't going anywhere soon, and the new vaccines are unlikely to get to us any time soon - if at all, given their need for advanced technology for storage and distribution. But we have seen our medical personnel, in all capacities, come to the fore and show their sheer brilliance, resilience, ingenuity and innovation in the face of a devastating disease. And this is not restricted to South Africa. Doctors in Kenya, for example, have weekly webinars to bring together those working outside Nairobi and discuss clinical and logistic issues around treating COVID-19 patients. Home-based care guidelines are being developed across the region, and communities in rural areas have come up with innovative ways to shield the vulnerable members of their villages and small towns. Senegal developed its own test kits, at a fraction of the cost of the imported ones, early in the pandemic, when only they and South Africa had COVID-19 testing capacity. Every country in Africa now has testing capacity. On a macro scale, I know from the work that I do for the WHO that the Regional Office in Brazzaville is now starting to convene workshops on how to use the information that we have collected from every country in the region to look at gaps and vulnerabilities in health and social systems and how to fill these. We are used to infectious disease outbreaks in Africa, and have pretty good surveillance systems in place to monitor and manage them. But this is the first time the entire region has been affected simultaneously, and we can learn from this experience, much as we did from the 2014 - 2016 Ebola virus disease outbreaks in West Africa. Enormous quantities of data have been collected, in innovative ways, which will now be used to examine healthcare delivery in the region. In spite of the economic and social devastation that this disease has visited on our continent, we can come out stronger. Thank you all for your support through this difficult year, and good health in 2021.

\section{Bridget Farham}

Editor

ugqirha@iafrica.com

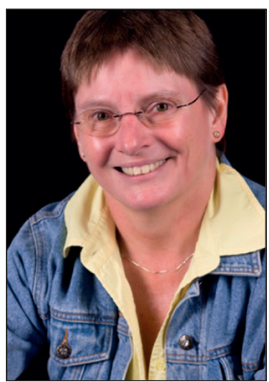

\footnotetext{
1. Wikipedia. COVID-19 pandemic in Europe. https://en.wikipedia.org/wiki/COVID-19_pandemic_in_ Europe (accessed 16 November 2020).

Wikipedia. COVID-19 in Lesotho. https://en.wikipedia.org/wiki/COVID-19_pandemic_in_Lesotho (accessed 16 November 2020).
}

COVID-19 Situation update for the WHO African Region, 11 November 2020. 